\section{$\underset{\substack{\text { hommes } \\ \text { \& migrations }}}{ }$}

\section{Hommes \& migrations}

Revue française de référence sur les dynamiques

migratoires

\section{$1293 \mid 2011$}

L'immigration dans les musées

\title{
Alan Stivell
}

\section{François Bensignor}

\section{(2) OpenEdition \\ Journals}

\section{Édition électronique}

URL : http://journals.openedition.org/hommesmigrations/537

DOI : 10.4000/hommesmigrations.537

ISSN : 2262-3353

\section{Éditeur}

Musée national de l'histoire de l'immigration

\section{Édition imprimée}

Date de publication : 1 septembre 2011

Pagination : 148-153

ISSN : 1142-852X

Référence électronique

François Bensignor, « Alan Stivell », Hommes \& migrations [En ligne], 1293 | 2011, mis en ligne le 29 mai 2013, consulté le 24 septembre 2020. URL : http://journals.openedition.org/hommesmigrations/537 ; DOI : https://doi.org/10.4000/hommesmigrations.537

Ce document a été généré automatiquement le 24 septembre 2020.

Tous droits réservés 


\title{
Alan Stivell
}

\author{
François Bensignor
}

\section{NOTE DE L'AUTEUR}

Le 16 février 2012 à l'Olympia, Alan Stivell fête le quarantième anniversaire du concert historique qui propulsa sa carrière vers les sommets nationaux et internationaux. C'est l'occasion de rappeler son rôle déterminant en faveur de la reconnaissance de la culture et de la langue bretonnes. L'occasion aussi de comprendre comment il servit de modèle à la génération folk des années soixante-dix en quête de ses racines culturelles, qu'elles soient occitanes, auvergnates, corses ou réunionnaises. En compagnie du harpeur breton, revisitons les débuts d'un parcours fait de passion, de travail, de joies et d'embûches.

1 On est frappé de constater qu'à ses débuts, la situation d'Alan Sitvell s'apparentait à celle que vivent aujourd'hui la plupart des immigrés de la deuxième génération. Issu d'une communauté humaine rejetée, méprisée à cause de sa culture, dans un pays qui pourtant est le sien, il lui fallut batailler longuement, ardemment, avant d'être accepté pour la qualité de son art. Afin d'y parvenir, il crée un style nouveau, mélangeant aux instruments traditionnels de Bretagne ceux de la pop. Sa manière de moderniser cette musique va constituer une source d'inspiration essentielle pour l'ensemble des courants qui se succéderont jusqu'à nos jours, en Bretagne comme dans les autres pays de culture celtique. Son combat en faveur de l'identité bretonne et de l'ouverture à la diversité va susciter bien d'autres vocations.

2 Si aujourd'hui le terme de "musique celtique" désigne un genre à part entière, reconnu sur les cinq continents, dans le contexte de l'après-guerre les spécialistes ne voyaient encore dans les pays de langue celte qu'une addition de folklores locaux, plus ou moins arriérés. L'usage de la langue bretonne, laminée par les politiques d'enseignement du français à l'exclusion de tout autre "dialecte", était considéré comme la survivance d'un archaïsme paysan. Contraintes à l'exil économique, plusieurs générations de Bretons ont dû s'assimiler à la vie terne des métropoles reconstruites après la Première, puis la 
Seconde Guerre mondiale. Dans les années cinquante, nombre d'entre eux souffrent de l'éloignement de leur famille, de leur langue et de leur culture. Parmi les cercles d'affinités qui les réunissent, le sentiment de leur identité culturelle donne une dimension beaucoup plus large aux revendications exprimées au pays parfois en termes par trop régionalistes et pas toujours "politiquement corrects", certains mouvements autonomistes ayant versé dans la collaboration.

Breton "immigré de la deuxième génération", Alan Cochevelou (du breton Kozh Stivellou "vieilles sources") - qui deviendra Stivell ("source jaillissante") en s'engageant dans le métier d'artiste au milieu des années soixante - est né à Riom en 1944 et a grandi dans le $\mathrm{XX}^{\mathrm{e}}$ arrondissement de Paris. Immergé dans la globalité urbaine qui mixe les individus, les sons et les cultures, il ressent dès l'enfance l'appel irrésistible de son identité bretonne.

"J'ai construit un amour tellement sans limites pour la Bretagne et la celtitude qu'en fait, je n'aime pas beaucoup Paris, explique Alan Stivell. J'ai une espèce de répulsion pour cette ville. C'est une situation qui serait à la limite du pathologique. Je pense que j'ai réussi à trouver ma thérapie dans mes créations, dans ma musique. Mes frères aînés fréquentaient eux aussi les cercles celtiques de Paris, mais je crois que j'étais parmi les plus extrêmes. Cette passion étonnait mes copains bretons et affolait mes copains de classe. Depuis le XX ${ }^{\mathrm{e}}$ arrondissement, le bus 96 m'amenait à Montparnasse. J'avais une sorte de fascination pour ce quartier parce que c'est à la fois le centre breton de Paris et celui de la gare pour partir en Bretagne. J'étais un enfant assez solitaire. Même dans la cour de récréation, je ne parlais pas beaucoup. Je vivais dans mon monde intérieur. Le fait d'entendre la musique du Maghreb, qu'elle soit arabe ou berbère, en passant devant les bistrots maghrébins, a certainement joué un rôle. C'était déjà une partie de ma culture. Une petite culture 'orientalisante' qui venait simplement de la proximité. Yves Montand, Édith Piaf, certaines formes de jazz et de variétés qui passaient à la radio à l'époque complétaient mon environnement qui n'a pas été seulement breton ou celtique."

\section{Renaissance de la harpe celtique}

4 Le père d'Alan, Jord Cochevelou, fait partie de ces militants passionnés qui veulent redonner son lustre à la culture celte. C'est ainsi qu'il se met en tête de recréer la petite harpe que jouaient autrefois les bardes irlandais et bretons. Banni d'Irlande par les Anglais au $\mathrm{XVI}^{\mathrm{e}}$ siècle, l'instrument avait disparu et plus un seul luthier contemporain n'en détenait les secrets de fabrication. En s'inspirant de gravures anciennes, Jord va reconstruire cette harpe perdue.

"Mon père a employé son temps de loisirs pendant un an pour réaliser cette harpe celtique. Il y avait un véritable suspense. On sentait la vie qui allait prendre dans cet être qui était la première harpe bretonne des temps modernes... Mon père ne m'a jamais dit: 'Tiens, c'est toi qui vas en jouer.' J'étais fasciné par cet instrument, et quand la première corde a été posée, c'est moi qui ai demandé. Je voulais tout de suite en jouer... C'était un amour fou, pour ce son et pour tout ce qu'il y avait autour... La fascination pour un monde mystérieux, aux confins de l'irréel. J'avais l'impression d'entrer dans la légende, dans la mythologie, dans l'au-delà. C'était quelque chose d'absolument inimaginable. Les pierres de Paris, à l'époque, étaient sales, toutes noires. Et dans ce monde très gris, tout d'un coup, une porte s'ouvrait sur un univers incroyable. C'est à partir de là que je me suis imprégné de culture celtique. J'ai commencé à ouvrir les bouquins de mon père, que je ne comprenais qu'à moitié. Parce que pour un enfant de neuf ans, ces écrits n'étaient pas toujours très lisibles." 
En 1953, Jord et son fils Alan réservent la découverte de ce nouveau modèle de harpe celtique au public de la Maison de la Bretagne, rue de l'Arrivée, dans le XIV arrondissement. Tout un apprentissage commence pour Alan, qui prend de vraies allures de quête.

"J'ai eu la chance de tomber sur la bonne prof de harpe, dit-il. Denise Mégevand, élève de Lily Laskine, était elle-même une personne passionnée. Elle avait une grande curiosité et une certaine souplesse pour imaginer l'évolution de la musique. Je crois qu'il y a eu une double séduction entre elle et moi. Elle partait d'un univers qui n'avait rien à voir avec la Bretagne. Et comme la tradition de la harpe celtique s'était éteinte depuis des siècles, il fallait entreprendre un travail de recréation: imaginer des musiques adaptées à l'instrument. Denise Mégevand a ainsi créé les premiers arrangements pour harpe celtique sur des thèmes bretons, irlandais, écossais, gallois, en étroite collaboration avec mon père et j'étais le cobaye."

En 1957, Alan foule pour la première fois les planches de l'Olympia à l'occasion d'un "Musicorama" consacré à Line Renaud. L'événement est relayé sur l'unique chaîne de télévision d'alors, où Jean Nohain présente le jeune prodige jouant d'un instrument ressuscité. Alan a 13 ans, sa harpe est son passeport, son idéal. À 15 ans, il enregistre son premier 45-tours de harpe celtique, à 20 ans son premier 33-tours.

\section{À l'école du bagad}

6 Au cours de son adolescence, Alan Stivell acquiert avidement cette culture bretonne, dont il est reconnu comme un porte-étendard. Les scouts bretons seront pour lui une formidable école de vie, de musique et de camaraderie. Dès l'âge de 10 ans, au sein du Bagad Bleimor, l'ensemble traditionnel des Bretons de Paris, il apprend la bombarde, puis le biniou bras.

“Je ne suis pas resté le solitaire que j'étais au départ, raconte le chanteur. J’ai appris à danser les danses bretonnes, à sonner en bagad. La musique de harpe n'est pas une véritable musique traditionnelle, mais une sorte de musique classique celtique. Et mon expérience en bagad m'a permis un enracinement dans la musique rurale traditionnelle bretonne. J'ai donc baigné dans cette musique populaire avec son pendant évolutif, en germe dans la musique de bagad, pendant plus de dix ans. Au début des années soixante, déjà un peu trop vieux pour être scout - même si on gardait l'uniforme avec les copains -, je ne m'intéressais plus qu'au bagad."

7 En l'espace de six ans, Alan Stivell franchit les échelons, brille dans les concours et devient "penn-soner" (premier sonneur). Il va se perfectionner au jeu de la cornemuse écossaise au College of Pipping de Glasgow, puis sera couronné champion de Bretagne à plusieurs titres : avec le Bagad Bleimor, dont il est devenu directeur musical, et en tant que sonneur en couple (biniou/bombarde) avec son acolyte Youenn Sicard (en 1966, 1968 et 1969). Par son art, Alan Stivell est décidé à révéler non seulement la beauté des musiques et des légendes, mais aussi des langues partagées par les peuples celtes. Dès son initiation à la bombarde, il ressent le besoin impérieux d'apprendre le breton pour échanger avec ses amis et connaissances. C'est dans cette langue chantante qu'il entend exprimer ses points de vue. Alors qu'il est étudiant à Paris à à la fac de Censier en anglais, il entreprend à Rennes un certificat de langues celtiques. 


\section{Le tremplin folk}

8 C'est l'époque où démarre à Paris le fameux "hootenanny" au Centre américain du boulevard Raspail, animé par Lionel Rocheman.

“'Hootenanny' est un mot amérindien qui désigne une veillée, une soirée, explique Alan Stivell. Le mardi soir, tout le monde pouvait venir chanter une ou deux chansons. C'était plutôt la mouvance folk américain avec un peu de chanson française à texte. Je suis entré dans cet univers-là avec ma harpe celtique et ça a formidablement bien fonctionné. J'ai perdu toutes les appréhensions que j'avais de me confronter à un public qui n'était plus composé d'une minorité bretonne. Des gens totalement étrangers à cette culture venaient m'écouter dans un silence religieux, pour entendre ma harpe qui avait un son très beau mais faible. Cela m'obligeait à chanter très doucement. Et cette confrontation avec ce public francoaméricain a été un point de départ. Des gens de radio m'ont entendu là, m'ont invité dans l'émission de Luc Bérimont à Radio France. Des maisons de disques m'ont entendu à la radio. Et en 1967, un an après avoir commencé à chanter, j'avais un contrat en poche."

9 Dès cette époque, Alan Stivell a l'idée d'une musique nouvelle, en phase avec son temps. Sa mise en forme prendra près de trois ans. Dans l'album Reflets (Fontana, 1970) brille enfin sa marque originale. Par son art, Alan souhaite avant tout révéler la beauté des cultures communes aux peuples locuteurs des langues gaéliques: Bretons, Galois, Irlandais, Écossais. Mais il entend aussi contribuer à forger cette nouvelle musique libératrice qu'appelle une jeunesse pressée d'en finir avec l'ère de destruction qu'ont vécue leurs parents. Le rock'n'roll de Chuck Berry, d'Elvis Presley a aussi contribué à forger son identité musicale. Il adore les guitares sidérales des Shadows et reste subjugué par la révolution pop des Beatles. Alan Stivell sera le premier à introduire la batterie, la basse et la guitare électriques dans la musique traditionnelle bretonne. L'univers d'évasion qu'il ouvre alors va séduire à la fois les amateurs de folk et la génération psychédélique.

\section{Chef de file du folk-rock}

Le concert à l'Olympia du 28 février 1972 est une surprise complète. Dans la salle bondée du music-hall parisien flottent des drapeaux bretons. Les spectateurs, avides, boivent les mots remplis de l'âme de la Bretagne. Les gorges se nouent lorsque sur An Alarc'h, son morceau de bravoure, résonnent les bombardes. Les doigts d'Alan Stivell, sobre en tunique blanche, cheveux noirs aux épaules, font surgir les mystères des fées sur sa petite harpe. Et quand batterie et basse déferlent avec une guitare électrique effrénée, un orgue pop et un violon folk, c'est un fameux pied de nez au passéisme d'une France post-impériale bouffie d'orgueil et dépassée par son temps que lance la jeunesse bretonne.

11 Sous ses allures réservées, Alan Stivell vient d'ouvrir la voie à l'un des plus importants courants de la musique populaire française des années soixante-dix: le folk-rock. Diffusé sur Europe $\mathrm{n}^{\circ} 1$, le concert "Musicorama" de l'Olympia produit une génération spontanée de jeunes groupes de musique bretonne dans tous les coins de France. Alan et son équipe de musiciens compétents - Dan Ar Braz à la guitare électrique, Gabriel Yacoub à la guitare et au chant, René Werneer au violon, Gérard Levasseur à la basse, Michel Santangeli à la batterie, etc. - sont accueillis en stars. En quelques mois, Stivell 
devient le héro d'une contre-culture soucieuse de préserver la diversité de la nature et des identités culturelles, porté par une jeunesse bien décidée à tout changer depuis l'explosion de mai 1968.

12 Le public français adopte rapidement le jeune chanteur breton, dont les spectacles égalent ceux des meilleurs groupes britanniques. L'auditeur lambda comprend implicitement l'engagement d'Alan Stivell pour la défense d'une culture menacée dans sa survie à cause du mépris infatué de décideurs incultes. Hérault de la culture celtique, il devient un exemple pour toutes les autres. Sur les plateaux télévisés des deux chaînes nationales, les animateurs, habitués à railler les "ploucs aux chapeaux ronds" que le prêt- à-penser médiatique fait alors rimer avec Bretons, accueillent, un rien condescendants, le chanteur à succès. C'est qu'à 30 ans, ce harpeur barbu, le triskell en sautoir et le breton aux lèvres, draine 40000 spectateurs au Palais des Sports de la Porte de Versailles à Paris et se produit à Londres au Queen Elisabeth Hall, comme à Dublin ou en tournée à travers les États-Unis. L'album Stivell à l'olympia (1972) sera vendu à plus d'un million et demi d'exemplaires de par le monde et figurera sur la liste des "500 meilleurs albums de tous les temps", publiée en 1983 par le magazine américain Rolling Stone.

Les foules qui acclament aujourd'hui le chanteur breton dans des stades en Allemagne, en Italie, en Australie et ailleurs, communient avec la puissance émotive du voyage imaginaire qui est au cœur de sa musique. Visionnaire par ses sonorités contemporaines, elle est l'écho de cultures anciennes, dont les valeurs perpétuées au long des siècles irriguent encore l'art et la pensée des sociétés actuelles. À travers la musique d'Alan Stivell, les enfants du xxI $^{e}$ siècle peuvent savourer les fruits de connaissances assimilées par les peuples voyageurs habitants des confins du monde occidental, en quête de terres lointaines, bien au-delà de l'horizon des océans.

\section{BIBLIOGRAPHIE}

Discographie sélective années soixante-dix

Renaissance de la harpe celtique (1972)

Stivell à l'Olympia (1972)

Chemins de terre (1973)

E Langonned (1974)

Dublin National Stadium - Live (1975) 